\title{
Hematopoietic Stem Cell Niches and Signals Controlling Immune Cell Development and Maintenance of Immunological Memory
}

\author{
Runfeng Miao ${ }^{\dagger}$, Vivian Y. Lim $^{\dagger}$, Neeharika Kothapalli ${ }^{\dagger}$, Yifan Ma, Julia Fossati, \\ Sandra Zehentmeier, Ruifeng Sun and João P. Pereira*
}

Department of Immunobiology and Yale Stem Cell Center, Yale University School of Medicine, New Haven, CT, United States

\section{OPEN ACCESS}

Edited by:

César Nombela Arrieta,

University of Zurich, Switzerland

Reviewed by:

Takashi Nagasawa,

Osaka University, Japan

Koji Tokoyoda,

German Rheumatism Research

Center (DRFZ), Germany

*Correspondence:

João P. Pereira

joao.pereira@yale.edu

${ }^{\dagger}$ These authors have contributed equally to this work

Specialty section:

This article was submitted to

Immunological Memory,

a section of the journal

Frontiers in Immunology

Received: 28 August 2020

Accepted: 29 October 2020

Published: 26 November 2020

Citation:

Miao R, Lim VY, Kothapalli N, Ma Y,

Fossati J, Zehentmeier S, Sun $R$ and

Pereira JP (2020) Hematopoietic Stem Cell Niches and Signals Controlling

Immune Cell Development

and Maintenance of

Immunological Memory.

Front. Immunol. 11:600127.

doi: 10.3389/fimmu.2020.600127
Studies over the last couple of decades have shown that hematopoietic stem cells (HSCs) are critically dependent on cytokines such as Stem Cell Factor and other signals provided by bone marrow niches comprising of mesenchymal stem and progenitor cells (MSPCs) and endothelial cells (ECs). Because of their critical roles in HSC maintenance the niches formed by MSPCs and ECs are commonly referred to as HSC niches. For the most part, the signals required for HSC maintenance act in a short-range manner, which imposes the necessity for directional and positional cues in order for HSCs to localize and be retained properly in stem cell niches. The chemokine CXCL12 and its Goi protein coupled receptor CXCR4, besides promoting HSC quiescence directly, also play instrumental roles in enabling HSCs to access bone marrow stem cell niches. Recent studies have revealed, however, that HSC niches also provide a constellation of hematopoietic cytokines that are critical for the production of most, if not all, blood cell types. Some hematopoietic cytokines, namely IL-7 and IL-15 produced by HSC niches, are not only required for lymphopoiesis but are also essential for memory $\mathrm{T}$ cell maintenance. Consequently, hematopoietic progenitors and differentiated immune cells, such as memory $T$ cell subsets, also depend on the CXCL12/CXCR4 axis for migration into bone marrow and interactions with MSPCs and ECs. Similarly, subsets of antibody-secreting plasma cells also reside in close association with CXCL12-producing MSPCs in the bone marrow and require the CXCR4/CXCL12 axis for survival and long-term maintenance. Collectively, these studies demonstrate a broad range of key physiological roles, spanning blood cell production and maintenance of immunological memory, that are orchestrated by stem cell niches through a common and simple mechanism: CXCL12/CXCR4-mediated cell recruitment followed by receipt of a maintenance and/or instructive signal. A fundamental flaw of this type of cellular organization is revealed by myeloid and lymphoid leukemias, which target stem cell niches and induce profound transcriptomic changes that result in reduced hematopoietic activity and altered mesenchymal cell differentiation.

Keywords: hematopoietic stem cell niches, lymphopoiesis, myelopoiesis, CXCR4, WHIM syndrome, leukemia 


\section{INTRODUCTION}

The hematopoietic system is composed of a multitude of cell types with different properties and functionalities. Hematopoietic cells develop from a rare population of hematopoietic-lineage restricted stem and progenitor cells that, in adult mammals, reside and differentiate in the bone marrow. Many studies over the last several decades have revealed a collection of extrinsic factors, such as cytokines and chemokines, that are required for hematopoietic stem and progenitor cell maintenance and activation. For the most part, these factors are locally produced in the bone marrow by a collection of cells that form the HSC niche. Several excellent reviews on the topic of stem cell niches have already been published $(1,2)$ and is not the focus of this review. Instead, we will focus on the bone marrow niches and signals involved in hematopoietic progenitor differentiation, as well as the bone marrow niches required for long term maintenance of adaptive immune cells. We will discuss a significant body of work showing that the niches controlling HSC maintenance overlap with the niches promoting lymphopoiesis and differentiation of at least some myeloid cell subsets. Furthermore, we will also discuss how these same niches play important roles in the maintenance of memory $\mathrm{T}$ cell subsets and long-lived plasma cells.

\section{INSTRUCTIVE SIGNALS AND NICHES CONTROLLING HEMATOPOIETIC CELL DIFFERENTIATION}

Hematopoietic stem and progenitor cells differentiate into lymphoid, myeloid, erythroid and megakaryocyte lineages in response to extracellular signals, predominantly cytokines, produced in the local microenvironment. Hematopoietic cytokines generally act to promote and/or maintain commitment to a specific cell lineage (e.g. lymphoid, myeloid, etc.), to induce progenitor cell proliferation, and/or to signal progenitor cell survival. Although some stochasticity is likely involved in HSC differentiation decisions, hematopoietic cell production is overtly reduced without access to lineage-specific hematopoietic cytokines. Therefore, the cellular sources of hematopoietic cytokines define the local microenvironments, or niches, where specific hematopoietic cell lineages are normally produced. We will focus on the cellular sources of key hematopoietic lineage-specific cytokines in bone marrow and on the guidance cues that allow hematopoietic progenitor cells to access these niches.

\section{Lymphoid Cells and Their Niches}

The lymphoid compartment is composed of $\mathrm{B}$ and $\mathrm{T}$ cell subsets (each greater than $10^{8}$ cells in mice) and of innate lymphoid cells (ILCs). All lymphoid subsets differentiate from lineage-restricted Common Lymphoid Progenitors (CLPs). CLPs express the interleukin (IL)-7 receptor complex formed by IL-7R $\alpha$ and the common $\gamma$ chain (3), and the large majority of lymphocyte subsets depend on IL-7/IL-7R signaling for their development and survival. Consequently, in IL-7 or IL-7R $\alpha$ deficient mice, B and T lymphocytes are reduced by 10-100 fold (4-6), and ILC subsets are also significantly reduced (7). Besides IL-7, FMS-like tyrosine kinase 3 ligand (FLT3L) has also been shown to contribute significantly to lymphopoiesis in that combined deficiency in IL-7 and FLT3L results in essentially undetectable $\mathrm{B}$ and $\mathrm{T}$ lymphocyte production (8-10). In terms of IL-7/IL-7R dependency, the single exception is Natural Killer (NK) cells, which are normally produced in IL-7-deficient mice but are overtly reduced in IL-15 or IL-15 receptor-deficient mice (1113). Although several other extrinsic factors have been found to play measurable roles in lymphopoiesis in vitro and/or in vivo (14), these cannot compensate for the absence of IL-7 or IL-15 and therefore will not be discussed here.

Both IL-7 and IL-15 act as short-range signals, necessitating proximity between lymphoid progenitor "client" cells and the cells producing them. IL-15 requires binding to its IL-15R $\alpha$ chain for trans-presentation to client cells expressing the IL-15 signaling receptor heterodimer formed by IL-2R $\beta$ and the common $\gamma$ chain. IL-7 acts as a soluble cytokine, but its expression is very low, and some evidence suggests that it can be tethered onto the cell surface through binding to glycosaminoglycans (15). For these reasons, a niche promoting IL-7-dependent lymphopoiesis exists in the vicinity of cells producing IL-7, and for NK cells the niche must be formed by the cells producing and/or presenting IL-15.

A study using Il15 reporter mice identified the cellular sources of IL-15 in the bone marrow as being mostly composed of CXCL12, VCAM1, and platelet-derived growth factor receptor beta (PDGFR $\beta$ )-expressing cells (16), which stands in agreement with prior studies that showed IL-15 expression in CXCL12+ stromal cells (17). Using a dual $I l 7$ and $I l 15$ reporter mouse, considerable overlap between the IL-7+ and IL-15+ mesenchymal stromal cell populations was discovered in bone marrow (16). Although insightful, these studies did not demonstrate that lymphoid progenitors were indeed dependent on IL-7 or IL-15 produced by mesenchymal stromal cells in vivo, as other cells, such as dendritic cells, can also produce IL-15 under inflammatory conditions (18).

Mesenchymal stem/progenitor cells (MSPCs) identified by surface expression of the Leptin receptor (LEPR) and PDGFR $\alpha / \beta$ constitute about $90 \%$ of all $I l 7$-expressing cells in the bone marrow, the remaining $10 \%$ being predominantly sinusoidal endothelial cells (19). Side-by-side comparison between Il7GFP knock-in reporter mice, and $I l 7$-cre recombinase mice crossed with Rosa26lox-stop-lox-YFP mice, a strategy that allows for cell lineage tracing of $I l 7$-producing cells and $I l 7$ past producer cells, also revealed that $I l 7$-expressing MSPCs differentiate into osteolineage cells, such as osteoblasts and osteocytes, that do not express $\mathrm{Il}$. Conditional $\mathrm{Il}$ deletion in MSPCs resulted in significant reduction of IL-7-dependent Blineage-committed CLP numbers, B cell progenitors, and overall reduced B cell production, whereas conditional $I l 7$ deletion in endothelial cells caused a small but significant reduction in proB and preB cell numbers that did not impact the overall size of the B cell compartment. Importantly, MSPC differentiation into osteolineage cells coincides with halted $I l 7$ expression, and 
thus, Il7 deletion from mature osteoblasts and osteocytes has no quantitative impact on B cell production (19). It should be noted that these findings diverge from prior studies proposing that osteolineage cells form a major niche for lymphopoiesis. However, these prior studies relied on mouse models in which osteolineage cells were selectively modified or ablated by conditional gene targeting approaches that presumed to be selective in osteoblasts but that are now known to act in MSPCs with variable efficiency. In depth analyses of these studies have recently been reviewed $(2,14)$.

An interesting feature of IL-7-producing MSPCs is that these cells express the highest amounts of CXCL12 in bone marrow (19). CXCR4, the CXCL12 receptor, attracts not only HSCs but also lineage-restricted hematopoietic progenitor cells, such as multipotent progenitor cells (MPPs), CLPs, and early B-lineage progenitor cells to the vicinity of MSPCs (19-21). HSCs require CXCR4/CXCL12 for long-term maintenance not only because CXCR4 signaling promotes HSC quiescence directly (20, 22-24) but also because it may enable cells to encounter Stem Cell Factor (SCF, encoded by Kitl). Consistent with this possibility, CXCL12+ cells and SCF+ stromal cells overlap by more than 99\%, and conditional Kitl or Cxcl12 deletion from MSPCs result in similar phenotypes: significant reductions in HSC numbers and hematopoietic reconstitution capacity (25-27). While direct evidence of reduced ckit signaling in CXCR4-deficient HSCs is still lacking. there is evidence supporting this model in downstream hematopoietic progenitors. Specifically, Cxcr4 conditional deletion in MPPs, or in CLPs, resulted in impaired lymphopoiesis due to a significant reduction in IL-7 receptor signaling, as measured by STAT5 phosphorylation (19). CXCR4 deletion at the B-lineage-committed proB cell stage also reduces developing $B$ cell numbers in the bone marrow due to their premature mobilization into the periphery (28-30), possibly in combination with reduced IL-7R signaling at the IL-7-dependent proB and preB cell stages. Likewise, CXCR4/CXCL12 plays essential roles in NK cell development as it presumably guides NK progenitors toward IL-15 niches formed by MSPCs (17).

But, CXCR4 signaling plays other roles than acting as a chemoattractant receptor. For example, CXCR4 signaling promotes conformational changes in the integrin heterodimer $\alpha 4 \beta 1$ (VLA-4) that result in its transactivation and adhesion to fibronectin and VCAM-1 $(31,32)$. Hematopoietic stem and progenitor cells, and lymphoid progenitors, are exquisitely dependent on $\alpha 4 \beta 1$ signaling for movement and retention within the bone marrow. Defects in integrin-mediated adhesion reduce hematopoietic stem and progenitor differentiation in bone marrow, in part due to their premature release into the bloodstream $(29,30,33,34)$. Furthermore, in vitro studies suggested that CXCR4 may also act as a signaling receptor capable of influencing cell decisions. CXCR4 signaling drives HSC proliferation directly via transcriptional control of cyclin D1 and MAD1 (23), and in preB cells, CXCR4 signaling activates ERK to facilitate Igk germline transcription (35).

Recent single cell transcriptomic analyses of nonhematopoietic bone marrow cells have provided unprecedented resolution of MSPC clusters and differentiation trajectories during homeostasis and leukemia (36-38). Collectively, these studies not only reinforce previous findings with Cxcl12, Kitl, Il7, and Il15 reporter mice described above, but also expand our knowledge of the repertoire of hematopoietic cytokines that are expressed by MSPCs and ECs in the bone marrow. For example, we now know that Flt3l, Csf1, and Il34, important myeloid cytokines, are primarily expressed by MSPC clusters that also express Il7, Il15 and Cxcl12 (37). Combined, these data support a model in which MSPCs not only control HSC maintenance and lymphopoiesis but may also control the development of essential myeloid cell subsets.

\section{Myeloid Cells and Their Niches}

Most myeloid cells develop from lineage-restricted common myeloid progenitors (CMPs), with the notable exception of megakaryocytes, which may have alternative developmental pathways (39), and mast cells, for which CMP and granulocyte-monocyte progenitors (GMP)-dependent and -independent pathways have been reported (40-44). In the classical model of hierarchical hematopoietic cell development, CMPs undergo differentiation into two major intermediate progenitors, GMPs and megakaryocyte-erythroid progenitors (MEPs), both of which retain cKit expression (the SCF receptor) at relatively high levels. Defects in Kit (encodes cKit) or in Kitl ultimately lead to reduced myelopoiesis in vitro and in vivo (45), but given the critical role this pathway plays in HSC maintenance, it is difficult to separate these effects from specific roles in myeloid progenitor maintenance and/or differentiation.

Phagocytes, such as neutrophils, basophils, eosinophils, and monocytes, differentiate from highly proliferative GMPs in response to cytokines such as macrophage colony-stimulating factor (M-CSF, encoded by Csf1), granulocyte-macrophage colony-stimulating factor (GM-CSF, encoded by Csf2), and granulocyte colony-stimulating factor (G-CSF, encoded by Csf3). Csf1 and Il34, which can signal through the M-CSF receptor (46), are critical for the development of monocytelineage cells in vivo, including bone resorbing osteoclasts (4749), and as mentioned earlier, are both primarily expressed by bone marrow MSPCs and some ECs. Like SCF, M-CSF can be produced in soluble and membrane-bound forms (50). Therefore, M-CSF-dependent cells likely require physical proximity to the cellular niches producing it. Consistent with this possibility, transgenic expression of the membrane-bound form of M-CSF in M-CSF-deficient op/op mice partially restores the development of several monocytic cell lineages including some tissue-resident macrophage populations and osteoclast progenitors $(51,52)$. Given the fact that CXCL12 is the most abundant chemoattractant produced by M-CSF-expressing cells, it is interesting to note that CXCR4 expression distinguishes early and proliferative M-CSF-dependent monocyte progenitor stages from the more mature inflammatory monocyte stage (53). Importantly, conditional CXCR4 deletion in MPPs resulted in significant reduction in inflammatory monocyte development (Miao et al. in preparation), which suggests that CXCR4/ CXCL12 plays a role in localizing monocytic cells in the proximity of monopoietic cytokines. In contrast to monocytic differentiation, osteoclast differentiation likely requires movement away from M-CSF niches (MSPC/EC) toward sources of RANKL produced by osteolineage cells (54-56). 
In adult mice, most dendritic cell (DC) subsets differentiate from a common monocyte/dendritic cell progenitor in response to two cytokines: M-CSF and FLT3L $(49,57)$. Although the bone marrow niches supporting DC development and DC lineage choices have not been functionally defined, the fact that both cytokines are predominantly expressed by MSPCs and some ECs in bone marrow suggests an overlap with HSC niches. Consistent with this model, plasmacytoid DCs depend on CXCR4/CXCL12 for development in bone marrow (58). Whether conventional or monocyte-derived DC subsets are also dependent on CXCR4 remains unclear.

Due to their very short life span (6-8 h in the resting state), neutrophils are the most abundantly produced granulocyte population with an estimated rate of $5-10 \times 10^{10}$ cells/day (59). G-CSF is the major cytokine promoting neutrophil development during both homeostasis and emergency states $(59,60)$. G-CSF acts at multiple stages during neutrophil development, starting at the GMP stage. A recent study examining GMP localization in bone marrow tissue noted that while GMPs are seemingly scattered throughout the bone marrow parenchyma under homeostasis, upon myelosuppressive treatment and leukemia, GMPs undergo proliferative bursts in large clusters around perivascular niches surrounded by lineage+ cells (61). GMP expansion during regeneration and leukemia was fueled by G-CSF, presumably secreted by sinusoidal endothelial cells, and by IL-1. The mechanisms of GMP clustering remain unstudied, but it is likely that CXCR4/CXCL12 plays some role in this process. Under homeostatic conditions, conditional CXCR4 deletion in MPPs (bypassing HSCs) reduced CMP, GMP and granulocyte production (19), which suggests that myeloid progenitor localization is important for myelopoiesis in vivo. Paradoxically, during systemic inflammation and infection, CXCL12 production is sharply decreased at the mRNA and protein levels along with reductions in lymphopoietic cytokine production $(62,63)$. These changes in CXCL12 levels primarily reduce the retention and production of lymphoid lineage cells in the bone marrow, presumably to allow for the expansion of short-lived myeloid cells required for protective immunity and return to homeostasis. However, reduced CXCL12 production would be expected to also reduce neutrophil (and monocyte) production (19). Nevertheless, G-CSF production is dramatically increased in the early stages of the systemic inflammatory response (64-66), which likely compensates for the negative effects of lower CXCL12 levels.

As for other granulocytes, the niches (and rules) controlling their development are less well-defined. Elegant studies using mice with thymic rudiments devoid of hematopoietic function (due to a mutation in the transcription factor Foxn1) showed that adding back SCF is sufficient to support mast cell differentiation in vivo (67), in agreement with prior in vitro studies (68). Whether this is also the case in the bone marrow microenvironment remains unknown. In contrast, SCF alone is insufficient for basophil and eosinophil development, as these phagocytes require specific instructive cues for their development. Basophil development is still poorly understood, but well-controlled in vitro studies demonstrated that combinations of SCF and IL-3, the latter secreted by mast cells, promote their development (68). Therefore, it is reasonable to consider that cellular circuits formed by granulocyte progenitors, mast cells and SCF/CXCL12+ niches in bone marrow generate an appropriate environment for basophil development. Eosinophil development is characterized by an intermediate eosinophil progenitor stage marked by low cKit and high IL-5R $\alpha$ expression, and is largely, but not entirely, dependent on IL-5 (69). In contrast to most hematopoietic cells, however, the majority of eosinophils do not differentiate in the bone marrow. Instead, they differentiate from eosinophil progenitors within peripheral tissues in response to IL-5 produced locally and primarily by ILC2 cells (70-72).

\section{Niches for Megakaryocytes and Erythrocytes}

While most hematopoietic cell lineages develop through welldefined stages, megakaryocyte development can take multiple pathways, including direct differentiation from HSC-like populations (39). Like all hematopoietic cell subsets, megakaryocyte development requires a combination of extrinsic cytokine signals for progenitor proliferation and differentiation into the final polyploid state. Early studies showed that thrombopoietin (encoded by Thpo) is the major cytokine that promotes megakaryopoiesis (73), and a recent elegant study showed that hepatocyte-derived, but not MSPC-derived thrombopoietin is essential for HSC maintenance and megakaryocyte development in vivo (74). However, the effects of thrombopoietin synergize with SCF in inducing megakaryocyte progenitor expansion and differentiation $(75,76)$. Whether such synergy can only occur in bone marrow niches or is also efficient in extramedullary sites is not entirely clear. Studies using CXCR4-deficient mice lend support to a model where megakaryocyte progenitor localization and differentiation takes place preferentially in bone marrow niches (77). Consistent with this model, CXCR4 expression is increased during megakaryocyte development (78), and these cells localize in perivascular niches in proximity to HSCs (79-81). In a similar manner, erythropoiesis relies on erythropoietin in synergy with SCF, which together coordinate the development of early uncommitted hematopoietic progenitors into erythroid lineagecommitted developmental stages (82). Given the dependency on cKit/SCF it is not surprising that CXCR4/CXCL12 deficiency in the hematopoietic lineage also leads to erythropoietic defects (77, $83,84)$.

\section{Bone Marrow Niches Supporting Adaptive Immunity}

Besides their critical function in HSC maintenance and hematopoietic progenitor differentiation, bone marrow niches formed by CXCL12+ cells are also instrumental for ensuring the longevity of adaptive immunity. Here, we will focus specifically on two major adaptive immune cell populations, plasma cells and memory $\mathrm{T}$ cell subsets.

\section{Plasma Cell Niches}

Plasma cells (PCs) are essential for humoral immunity against infections and can be divided into two sub-populations: shortlived and proliferative plasmablasts, and long-lived and quiescent 
plasma cells (LLPCs). A large fraction of LLPCs reside in bone marrow and provide the body with long-term protection via constitutive antibody production (85-87). Besides the bone marrow, LLPCs also reside in secondary lymphoid organs, the gastrointestinal tract, and other mucosal-associated tissues (88). The microenvironments where LLPCs reside are thought to play important roles in LLPC survival because these cells lack the intrinsic ability to survive in the absence of extrinsic factors (89, 90). LLPC survival factors include ligands for the TNF superfamily member BCMA (B cell maturation antigen, gene symbol Tnfrsf17), namely B cell activation factor (BAFF, encoded by $T n f s f 13 b$ ) and a proliferation-inducing ligand (APRIL, encoded by Tnfsf13), several cytokines of which IL-6 plays a prominent role, costimulatory B7 family members CD80 and CD86, CD44, CXCL12, and adhesion receptors (91).

PC survival factors can be divided into two groups: signals that directly control the expression of anti-apoptotic molecules (e.g. Bcl2 family members) and factors that control PC localization in appropriate niches (e.g. chemokines, adhesion receptors). Of the signals that directly promote PC survival, BCMA is perhaps the most impactful as BCMA-deficient mice show the largest reduction in antigen-specific PC numbers in the bone marrow $(92,93)$. Consistent with such a prominent role, BCMA signaling induced by BAFF or APRIL promotes the expression of the anti-apoptotic Bcl2 family member, Mcl1 (93, 94). Interestingly, the dependence on BCMA for PC survival is tissue-specific, as BCMA does not control the expression of $\mathrm{Mcl} 1$ or other Bcl2-family members in splenic PCs, and BCMAdeficiency does not reduce splenic PC numbers (93).

BAFF and APRIL bind to BCMA $(95,96)$ with APRIL binding with higher affinity $(97,98)$. The loss of both signals impairs PC survival in bone marrow $(94,96)$. BAFF is produced by myeloid precursors and neutrophils $(99,100)$, and APRIL is expressed by myeloid precursors, monocytes/macrophages, eosinophils and megakaryocytes in bone marrow (99-103). PCs have been found in close proximity with cells expressing BCMA ligands in bone marrow, and genetic models of megakaryocyte or eosinophil deficiency revealed small but significant reductions in bone marrow PC numbers (99-103). Besides BCMA ligands, myeloid cells may also provide other soluble and membranebound PC survival signals such as CD28 ligands and cytokines, which in the case of IL-6 can synergize with APRIL or other soluble factors secreted by stromal cells to extend PC survival (104). In turn, in vitro studies showed that interactions between PCs and stromal cells induced further IL-6 production (89). Similarly, secretion of IL- 6 by DCs can also be induced by interactions with PCs through CD28-CD80/CD86 (105). These findings suggest that positive feedforward mechanisms driven by complex cellular interactions between PCs and niche cells may operate in vivo in a manner reminiscent of cell circuits between proB cells and IL-7-producing MSPCs (14, 21). However, it should be noted that very few MSPCs, osteolineage cells, and endothelial cells in bone marrow express IL-6 in vivo under homeostatic conditions (37), and that single deficiency in Il6 does not cause measurable reductions of PC numbers in vivo (90).
Although some PCs may be able to differentiate in the bone marrow environment $(106,107)$, the large majority of PCs differentiate from activated B cells in secondary lymphoid organs and require a coordinated change in chemoattractant responsiveness to migrate into the bone marrow $(108,109)$. CXCR4 in particular is essential for PC homing into the bone marrow (110) and once inside this compartment, PCs localize adjacent to CXCL12-expressing cells (111) where they remain relatively static over short periods of time (112). The mechanisms underlying this non-motile behavior have not been elucidated but it is likely the result of high CXCR4 signaling in combination with integrin-mediated adhesion, namely $\alpha 4 \beta 1$ - and $\alpha \mathrm{L} \beta 2$-mediated interactions with fibronectin and ICAM1 expressed on CXCL12producing cells $(89,113)$. Signaling induced by $\alpha \mathrm{L} \beta 2$ and $\alpha 4 \beta 1$ activation may also prevent apoptosis via the phosphatidylinositol3-kinase (PI3K)-protein kinase B (AKT) pathway $(114,115)$. Besides myeloid lineage cells, perivascular DCs also localize in CXCL12+ niches (116) and may contribute to PC survival via direct delivery of CD80 and CD86 signals (105). Combined, these studies demonstrate that a complex network of cells and signals promote PC survival and suggest that PC localization in bone marrow niches is a pre-requisite for receiving survival signals.

But, can PCs destined to reside in bone marrow niches survive elsewhere? The answer varies by the type of PC. Under conditions of acute immunization with model antigens, PCs specific for T-independent antigens depend on CXCR4 for homing into the bone marrow. Accordingly, defects in this process result in decreased PC numbers in bone marrow and reduced antigen-specific IgM and IgG production. PCs developing from $\mathrm{T}$-dependent antigens from acute immunizations also require CXCR4 for bone marrow homing, but serum antigen-specific IgM, IgG and IgA concentrations remain normal (28). These data lend strong support to a model where LLPCs generated from acute immunizations destined for bone marrow niches can survive in peripheral sites and secrete antigen-specific antibodies for extended periods of time (117). Hence, PC localization in bone marrow niches may play other roles that are independent of antibody secretion $(118,119)$.

\section{Bone Marrow Niches for T Cells}

Most lymphoid organs contain large numbers of naïve $\mathrm{T}$ cells due to the activity of transcriptional programs controlled by Krüppel-like Factor 2 (KLF2), which coordinates the expression of a key set of genes responsible for T cell trafficking $(120,121)$. Naïve T cell re-circulation is essential for naïve $\mathrm{T}$ cell survival due to the fact that these cells depend on external signals, such as IL-7 and Sphingosine 1-phosphate (S1P), for homeostatic survival $(122,123)$. While both of these signals could theoretically be provided in bone marrow niches, naïve $\mathrm{T}$ cells seldom migrate into this compartment due to very low CXCR4 expression, a process that is actively regulated by Sin1-dependent mammalian target of rapamycin complex-2 (mTORC2) signaling and FOXO1 inactivation (124). The signals upstream of mTORC2FOXO1 remain undefined. The bone marrow is, however, a reservoir for some $\mathrm{T}$ cell subsets. Long-lived CD4+ and CD8+ central memory (CM) $\mathrm{T}$ cells undergo cytokine-driven 
homeostatic self-renewal to ensure long-term maintenance of the memory T cell pool. CM CD8+ T cells mainly depend on IL-15 for homeostatic self-renewal, whereas CM CD4+ T cells are more dependent on IL-7 than IL-15 $(125,126)$. Even though sources of IL-7 and IL-15 exist in multiple organs throughout the body (16, 127-129), as previously discussed, both cytokines are also produced by bone marrow MSPCs (37). Importantly, CXCR4mediated homing to the bone marrow is essential for the survival of CM T cells (130-133).

Given the fact that CM lymphocytes reside in the bone marrow and share niches with HSCs and their descendants, mechanisms have evolved to keep antigen-experienced lymphocytes under control. Regulatory T cells (Tregs), a T cell population that is essential for immune tolerance, seem to play such roles in bone marrow niches. Under homeostatic conditions, Tregs account for $20 \%$ to $40 \%$ of CD $4+\mathrm{T}$ cells in bone marrow. Bone marrow Tregs differ from peripheral Tregs in their increased ability to express IL-10 and the checkpoint receptor CTLA-4 (134). This is particularly relevant in bone marrow transplantation, where Tregs have been described to promote tolerance to allogeneic HSCs (135). In the scurfy mouse model, Treg deficiency results in profoundly abnormal hematopoiesis (136), although it is difficult to separate local effects in the bone marrow microenvironment from systemic inflammation and the ensuing emergency myelopoiesis $(60,62$, 63). Besides their role in maintaining peripheral tolerance, some evidence suggests that Tregs can also directly control the homeostasis of several hematopoietic cell lineages. For example, bone marrow Tregs promote HSC quiescence via adenosine secretion (137), although it is unclear if this is through direct crosstalk with HSCs, or through indirect effects on CM and other $\mathrm{T}$ cell subsets. Tregs also promote LLPC survival and osteoclast differentiation through CTLA-4 (134). The fact that Tregs maintain a state of immune privilege in bone marrow for the homeostasis of HSCs and other hematopoietic cells provides another elegant example of the multifunctionality of HSC niches in bone marrow.

\section{LESSONS FROM WHIM SYNDROME}

A key feature of most cellular receptors is their ability to undergo ligand-induced receptor internalization and signal termination. This is particularly relevant for physiological control of chemoattractant receptor function as it allows cells to desensitize from one chemoattractant and respond to other cues emanating from adjacent locations $(138,139)$. More than $95 \%$ of hematopoietic cells in bone marrow express CXCR4 and migrate toward sources of CXCL12. Most, if not all, hematopoietic cell lineages utilize the CXCR4/CXCL12 pathway during development from HSCs and downstream multipotent progenitors. Like most chemoattractant receptors, CXCR4 is internalized upon binding to CXCL12, and CXCR4 desensitization is an important mechanism of controlled hematopoietic cell exit from the bone marrow (33). Defects in CXCR4 desensitization alone can cause numerous physiological defects in hematopoietic cell development and recirculation that result in immune deficiency, as evidenced by patients afflicted with WHIM syndrome.

WHIM syndrome is an extremely rare combined immunodeficiency disorder caused predominantly by heterozygous nonsense and missense mutations in the cytoplasmic tail of CXCR4, the most common being the replacement of Arginine 334 by a stop codon, which deletes the last 19 amino acids of the C-terminus domain $(140,141)$. The cytoplasmic domain controls CXCR4 desensitization by recruiting GPCR kinases (GRKs) followed by phosphorylation of serine/threonine residues and $\beta$-arrestin recruitment (142, 143). Therefore, mutations in the cytoplasmic tail of CXCR4 are typically gain-of-function, resulting in increased CXCR4 signaling in response to its ligand CXCL12 (144). The frequency of WHIM syndrome is estimated to be 0.23 per million births (145). The WHIM acronym is defined by disease symptoms: Warts, Hypogammaglobulinemia; Infections, which are common in the respiratory and mucosal tracts, patients being particularly susceptible to Human Papilloma Virus infections; and Myelokathexis, the retention of neutrophils in bone marrow that is responsible for very low neutrophil counts in peripheral blood. Most patients also present with peripheral blood panleukopenia, particularly B lymphopenia and a paucity of plasmacytoid dendritic cells (Majumdar and Murphy, 2018).

Given the dominant effects of CXCR4/CXCL12 at multiple stages of hematopoietic cell development, gain-of-function mutations in CXCR4 are also expected to impact blood cell production. A mouse model of WHIM syndrome generated by Balabanian and colleagues reproduced several hematological defects seen in WHIM patients, including peripheral blood leukopenia, that could be reversed by CXCR4 antagonism (146). Likewise, WHIM patients treated with a low dose of a CXCR4 antagonist also restore leukocyte numbers in peripheral blood and have reduced susceptibility to infectious diseases (147). In the WHIM mouse model, peripheral blood leukopenia was mostly caused by reduced $B$ cells and neutrophils. Besides mature B cells, CD4 and CD8 T cells were also significantly reduced in the spleen, suggesting defective $\mathrm{B}$ and $\mathrm{T}$ cell development in primary lymphoid organs. In contrast, neutrophil development was seemingly intact, with mature neutrophils being somewhat increased in the bone marrow perhaps as a consequence of reduced egress from this compartment (146).

A combination of serendipity and careful molecular and cellular studies of a single WHIM patient revealed surprising insights into the delicate balance between HSC quiescence, activation, and multilineage differentiation. Identified at the $\mathrm{NIH}$ as patient WHIM-09, this patient spontaneously cured leukopenia and susceptibility to infectious diseases, due to a chromothripsis event in chromosome 2 of presumably a single hematopoietic progenitor cell, which eliminated the $C x c r 4^{R 334 X}$ allele along with 163 other genes and switched a hyperresponsive for an haploinsufficient CXCR4 state (148). Studies in mice showed competitive advantage in hematopoietic reconstitution of HSCs haploinsufficient for CXCR4, thus providing a plausible explanation for why chromotryptic 
"cure" of Cxcr $4^{R 334 X}$ allele in a single hematopoietic progenitor resulted in the replacement of leukocytes expressing the R334X mutant CXCR4 by the single wild-type allele (148). Paradoxically, in the WHIM-09 patient, lymphoid cells only differentiated from R334X-expressing hematopoietic progenitors, while myeloid cells differentiated from hematopoietic progenitors expressing wild-type CXCR4, albeit at reduced amounts due to CXCR4 haploinsufficiency. The fact that short-lived myeloid cells such as neutrophils are only produced by CXCR4 wild-type expressing hematopoietic progenitors decades after chromothripsis occurred strongly suggests that deletion of the $C x c r 4^{R 334 X}$ allele occurred in a single HSC, which expanded and self-renewed over time. However, this model is not easily compatible with the fact that lymphoid lineage cells develop from hematopoietic progenitors carrying $C x c r 4^{R 334 X}$ alleles. One possibility is that one or several of the 163 genes deleted are directly or indirectly critical for lymphopoiesis. Alternatively, expression of hyper-responsive R334X CXCR4 in a few hematopoietic progenitors diluted in a sea of hematopoietic stem and progenitor cells expressing $50 \%$ of wild-type CXCR4 confers a very strong competitive advantage for contacts with niche cells providing lymphopoietic factors (19, 21 ). It should be noted that lymphoid progenitors are particularly sensitive to efficient CXCR4 desensitization for their proper development from hematopoietic progenitors (149), and thus studies are needed to fully understand how changes in CXCR4 signaling intensity translates into alterations in hematopoietic cell lineage decisions.

\section{LEUKEMIA AND ITS IMPACT ON BONE MARROW NICHES, HEMATOPOIESIS, AND IMMUNE CELLS}

The tight regulation over cell proliferation, differentiation, and quiescence carried out by the HSC niche is severely disrupted in the context of malignancy (150). Studies over the last few years have revealed that several types of blood cancers interact with MSPCs and ECs and alter their ability to produce homeostatic cytokines and chemokines. Mouse models of chronic myelogenous leukemia (CML) showed significant reductions in the expression of HSC niche factors, including Cxcl12, Lepr, Kitl and Angpt1, and concomitant expansion of osteolineage cells $(151,152)$. The expansion of osteolineage cells contributed to bone marrow fibrosis, a phenomenon also observed in CML patients (153). These observations have been reinforced by single-cell RNA-sequencing of stromal and endothelial cells of mice transplanted with acute myeloid leukemia (AML), which revealed a block in adipogenic and osteogenic differentiation programs in MSPCs and osteolineage cells, as well as a reduction of Cxcl12 and Kitl in MSPCs and arteriolar ECs (36). In addition, Angpt1 and Il7 expression in MSPCs was also decreased. Furthermore, in myeloproliferative neoplasms (MPNs), hyperactivated hedgehog $(\mathrm{HH})$ signaling, predominantly driven by the overproduction of $\mathrm{HH}$ ligands by malignant cells, results in decreased numbers of bone marrow MSPCs and osteoblasts and the downregulation of niche-derived HSCmaintenance factors (154). Specifically, Kitl and Cxcl12 are downregulated especially in endothelial cells and CXCL12abundant reticular (CAR) cells, and Jagged1 is downregulated in endothelial cells (154).

Besides myeloid malignancies, lymphoid malignancies have also been shown to alter the bone marrow microenvironment. An early study using adoptive transfer of the Nalm6-GFP preB Acute Lymphoblastic Leukemia (ALL) cell line found reduced Cxcl12 expression in poorly-defined bone marrow niches, resulting in displacement of normal hematopoietic stem and progenitor cells (155). More recently, our group demonstrated that pre-malignant preB cells with unrepaired double-stranded DNA breaks induce the downregulation of $I l 7$ transcription in bone marrow MSPCs, while BCR-ABL preB ALL cells downregulate both $I l 7$ and Cxcl12 in MSPCs via undefined mechanisms (21).

In addition to the reduced expression of key niche factors, the overproduction of pro-inflammatory cytokines by niche cells has also been observed in the early stages of multiple hematological malignancies. IL-1 $\beta$ is one of the first pro-inflammatory cytokines abnormally increased in the development of MPN and CML in mice (156), and clinically, such elevated levels of IL$1 \beta$ in CML patients have been associated with poor prognosis (157). Other cytokines and growth factors such as IL-6, thrombopoietin, and CCL3 have also been suggested to render the bone marrow microenvironment pro-inflammatory in AML, ALL, MPN, and CML (152, 156, 158, 159).

This pro-inflammatory milieu disrupts normal HSC niche function primarily in two ways. First, it damages sympathetic nerve fibers that innervate arterioles, which are essential for maintaining MSPC quiescence $(156,160)$. In AML, sympathetic neuropathy has been correlated with skewed Nestin (gene symbol Nes)-producing niche cell fate determination, wherein MSPCs primed for the osteoblastic lineage significantly expand at the expense of HSC-maintaining arteriole-associated Neuronglial antigen 2 (NG2)-expressing niche cells (161). Second, the inflammatory signals, possibly in combination with $\mathrm{HH}$ signaling, reduce CXCL12 expression in niche cells (151, $156,161)$.

Together, these niche changes impair normal hematopoiesis while favoring the growth of leukemic malignancies (21, 161-163). In AML patients, total hematopoietic progenitors (CMPs, GMPs and MEPs) are reduced (164), and likewise, bone marrow samples from pediatric cases of ALL have lower levels of myeloid progenitor cells and erythroid progenitor cells than control samples (158). One possible explanation for the selective growth of leukemic cells is that other pathways could complement the CXCR4/CXCL12 axis in malignant cells to enable their migration. For instance, some studies have shown that Bruton's Tyrosine Kinase (BTK) signaling is important for mediating leukemic cell migration toward CXCL12 in chronic lymphocytic leukemia and multiple myeloma $(165,166)$. As such, malignant cells may have an advantage in the competition for niche occupancy when CXCL12 concentration becomes limiting. Furthermore, other studies have shown that as leukemia progresses, leukemic cells 
become less dependent on certain niche factors than normal hematopoietic cells. For example, while pre-leukemic stem cells (LSCs) in AML are highly dependent on niche-derived Winglesstype (Wnt) signals in a manner similar to long-term HSCs, established LSCs and AML are unresponsive to Wnt inhibitors due to cell-intrinsic activation of Wnt signaling (167). Hence, AML cells downregulate niche factors to which normal hematopoietic cells are more sensitive, possibly as a method to gain a competitive advantage.

On the other hand, defects in the bone marrow microenvironment can themselves initiate the development of hematopoietic malignancies (150). Activating mutations of the protein tyrosine phosphatase SHP2 in MSPCs marked by Nescre, Prx1-cre, Lepr-cre or Osx-cre all result in MPNs, in part due to excessive production of CCL3 by MSPCs (168). In addition, deletion of Dicer1 in Osx-cre-expressing MSPCs led to myelodysplasia and even AML in a small percentage of mice (169). In this case, Dicer1 deficiency resulted in reduced expression of Sbds, the gene that is mutated in SchwachmanBodian-Diamond syndrome, a human bone marrow failure and leukemia pre-disposition condition. Importantly, deletion of Sbds using Osx-cre also led to myelodysplasia. In other studies, Sipal and retinoic acid receptor gamma $(\operatorname{RAR} \gamma)$ deficiency in radio-resistant cells led to the development of myeloproliferative syndromes $(170,171)$. Interestingly, an activating mutation of beta-catenin in mouse osteoblasts led to the development of AML, where wild type hematopoietic stem and progenitor cells acquired chromosomal aberrations and the ability to propagate disease autonomously even after transplantation into a wild type environment (172). This demonstrates that dysregulation of the bone marrow niche can even enable the transformation of mutant hematopoietic cells.

In summary, leukemic cells can cause profound transcriptional changes in critical bone marrow niche cells, though the molecular mechanisms underlying these alterations remain poorly defined. It is possible that the molecular crosstalk between malignant cells and the bone marrow niche gradually remodels normal niche behavior to foster leukemic growth and attenuate normal hematopoiesis. Also poorly understood is whether leukemias affect the long-term maintenance of adaptive immune cells that require access to critical bone marrow survival niches, though recent studies suggest that may be the case $(173,174)$.

\section{CONCLUDING REMARKS AND UNANSWERED QUESTIONS}

The bone marrow niches formed by MSPCs and endothelial cells provide an array of soluble and membrane-bound cytokines and chemoattractants that not only control HSC maintenance but also support hematopoietic progenitor commitment into multiple hematopoietic cell lineages. Besides orchestrating unperturbed hematopoiesis, these niches also contribute to long-term maintenance of immunological memory through the production of key homeostatic cytokines such as IL-7 and IL-15.
These observations raise a number of physiologically relevant questions: What factors and mechanisms control the size of the HSC compartment under homeostasis? Is there direct competition between HSCs, hematopoietic multipotent progenitors, and adaptive immune cells for common factors, and if so, how is homeostasis of each cellular compartment achieved? HSCs, hematopoietic progenitors, plasma cells and memory $\mathrm{T}$ cells are critically dependent on CXCR4 for bone marrow homing, and therefore it is likely that these cells compete for proximity or even direct contact with niche cells. Consistent with this model, CXCL12 production is highest in MSPCs producing critical HSC maintenance factors and cytokines. However, there is evidence indicating that HSC niches are not saturated and can sustain up to 2- to 3 -fold increased numbers of HSCs for extended periods of time (175). It is possible that heterogeneous production of additional chemoattractants may control the differential localization of HSCs, hematopoietic progenitors, and adaptive immune cells in the proximity of distinct niche cells. Future studies are needed to further examine the intricate relationship between HSCs, hematopoietic progenitors, and terminally differentiated immune effector cells. The recent advances in HSC visualization in vivo should allow these questions to be addressed $(34,176)$.

An increasing body of work strongly indicates that the production of hematopoietic cytokines and chemoattractants by HSC niche cells is regulated by soluble inflammatory cytokines (e.g. TNF $\alpha$, IL-1 $\beta$ ), but may also be regulated by other cues provided by leukemic cells. The fact that inflammation induces a switch in blood cell production from homeostatic and balanced lymphoid and myeloid production to an emergency state of increased myelopoiesis suggests that these distinct cell lineages compete for limiting factors in the local microenvironment. Leukemic cells and non-leukemic hematopoietic cells are also likely to compete for certain types of factors (e.g. anabolic nutrients) such that leukemic cells may exploit hard-wired mechanisms of cytokine/chemokine production to gain competitive advantage by reducing the fitness of non-leukemic hematopoietic progenitors. Furthermore, it is still unclear if leukemia or inflammationinduced changes in cytokine/chemokine production by individual niche cells are reversible, or if altered cytokine/ chemokine production is coordinated with niche cell differentiation and/or survival. Future studies addressing these questions are likely to uncover novel mechanisms and pathways that may be applied therapeutically to reduce leukemic cell competitive advantages, to improve HSC transplantation, and to enhance the lifespan of immunological memory against pathogens.

\section{AUTHOR CONTRIBUTIONS}

RM, VL, and NK made extensive review of the literature listed and drafted different sections of the review. YM and JF drafted a section of the review focused on the WHIM syndrome with help 
from SZ. RS drafted a section of the review focused on blood cell malignancies with help from NK. JP wrote the manuscript with input from all authors. All authors contributed to the article and approved the submitted version.

\section{REFERENCES}

1. Morrison SJ, Scadden DT. The bone marrow niche for haematopoietic stem cells. Nature (2014) 505:327-34. doi: 10.1038/nature12984

2. Wei Q, Frenette PS. Niches for Hematopoietic Stem Cells and Their Progeny. Immunity (2018) 48:632-48. doi: 10.1016/j.immuni.2018.03.024

3. Kondo M, Weissman IL, Akashi K. Identification of clonogenic common lymphoid progenitors in mouse bone marrow. Cell (1997) 91:661-72. doi: 10.1016/S0092-8674(00)80453-5

4. von Freeden-Jeffry U, Vieira P, Lucian LA, McNeil T, Burdach SE, Murray R. Lymphopenia in interleukin (IL)-7 gene-deleted mice identifies IL-7 as a nonredundant cytokine. J Exp Med (1995) 181:1519-26. doi: 10.1084/ jem.181.4.1519

5. Puel A, Ziegler SF, Buckley RH, Leonard WJ. Defective IL7R expression in T(-) $\mathrm{B}(+) \mathrm{NK}(+)$ severe combined immunodeficiency. Nat Genet (1998) 20:394-7. doi: $10.1038 / 3877$

6. Carvalho TL, Mota-Santos T, Cumano A, Demengeot J, Vieira P. Arrested B lymphopoiesis and persistence of activated B cells in adult interleukin 7(-/)mice. J Exp Med (2001) 194:1141-50. doi: 10.1084/jem.194.8.1141

7. Spits H, Di Santo JP. The expanding family of innate lymphoid cells: regulators and effectors of immunity and tissue remodeling. Nat Immunol (2011) 12:21-7. doi: $10.1038 /$ ni.1962

8. Sitnicka E, Brakebusch C, Martensson IL, Svensson M, Agace WW, Sigvardsson $\mathrm{M}$, et al. Complementary signaling through flt3 and interleukin7 receptor alpha is indispensable for fetal and adult B cell genesis. J Exp Med (2003) 198:1495-506. doi: 10.1084/jem.20031152

9. Jensen CT, Boiers C, Kharazi S, Lubking A, Ryden T, Sigvardsson M, et al. Permissive roles of hematopoietin and cytokine tyrosine kinase receptors in early T-cell development. Blood (2008) 111:2083-90. doi: 10.1182/blood-200708-108563

10. Jensen CT, Kharazi S, Boiers C, Cheng M, Lubking A, Sitnicka E, et al. FLT3 ligand and not TSLP is the key regulator of IL-7-independent B-1 and B-2 B lymphopoiesis. Blood (2008) 112:2297-304. doi: 10.1182/blood-2008-04-150508

11. Suzuki H, Duncan GS, Takimoto H, Mak TW. Abnormal development of intestinal intraepithelial lymphocytes and peripheral natural killer cells in mice lacking the IL-2 receptor beta chain. J Exp Med (1997) 185:499-505. doi: 10.1084/jem.185.3.499

12. Kennedy MK, Glaccum M, Brown SN, Butz EA, Viney JL, Embers M, et al. Reversible defects in natural killer and memory CD8 T cell lineages in interleukin 15-deficient mice. J Exp Med (2000) 191:771-80. doi: 10.1084/ jem.191.5.771

13. Dubois S, Mariner J, Waldmann TA, Tagaya Y. IL-15Ralpha recycles and presents IL-15 In trans to neighboring cells. Immunity (2002) 17:537-47. doi: 10.1016/S1074-7613(02)00429-6

14. Zehentmeier S, Pereira JP. Cell circuits and niches controlling B cell development. Immunol Rev (2019) 289:142-57. doi: 10.1111/imr.12749

15. Clarke D, Katoh O, Gibbs RV, Griffiths SD, Gordon MY. Interaction of interleukin 7 (IL-7) with glycosaminoglycans and its biological relevance. Cytokine (1995) 7:325-30. doi: 10.1006/cyto.1995.0041

16. Cui G, Hara T, Simmons S, Wagatsuma K, Abe A, Miyachi H, et al. Characterization of the IL-15 niche in primary and secondary lymphoid organs in vivo. Proc Natl Acad Sci USA (2014) 111:1915-20. doi: 10.1073/ pnas.1318281111

17. Noda M, Omatsu Y, Sugiyama T, Oishi S, Fujii N, Nagasawa T. CXCL12CXCR4 chemokine signaling is essential for NK-cell development in adult mice. Blood (2011) 117:451-8. doi: 10.1182/blood-2010-04-277897

18. Mattei F, Schiavoni G, Belardelli F, Tough DF. IL-15 is expressed by dendritic cells in response to type I IFN, double-stranded RNA, or lipopolysaccharide and promotes dendritic cell activation. J Immunol (2001) 167:1179-87. doi: 10.4049/jimmunol.167.3.1179

\section{FUNDING}

This study was funded by the NIH (grants R01 AI11304006A1 and R21AI146648).

19. Cordeiro Gomes A, Hara T, Lim VY, Herndler-Brandstetter D, Nevius E, Sugiyama T, et al. Hematopoietic Stem Cell Niches Produce LineageInstructive Signals to Control Multipotent Progenitor Differentiation. Immunity (2016) 45:1219-31. doi: 10.1016/j.immuni.2016.11.004

20. Sugiyama T, Kohara H, Noda M, Nagasawa T. Maintenance of the hematopoietic stem cell pool by CXCL12-CXCR4 chemokine signaling in bone marrow stromal cell niches. Immunity (2006) 25:977-88. doi: 10.1016/ j.immuni.2006.10.016

21. Fistonich C, Zehentmeier S, Bednarski JJ, Miao R, Schjerven H, Sleckman BP, et al. Cell circuits between B cell progenitors and IL-7(+) mesenchymal progenitor cells control B cell development. J Exp Med (2018) 215:2586-99. doi: $10.1084 /$ jem.20180778

22. Nie Y, Han YC, Zou YR. CXCR4 is required for the quiescence of primitive hematopoietic cells. J Exp Med (2008) 205:777-83. doi: 10.1084/jem. 20072513

23. Omatsu Y, Sugiyama T, Kohara H, Kondoh G, Fujii N, Kohno K, et al. The Essential Functions of Adipo-osteogenic Progenitors as the Hematopoietic Stem and Progenitor Cell Niche. Immunity (2010) 33:387-99. doi: 10.1016/ j.immuni.2010.08.017

24. Tzeng YS, Li H, Kang YL, Chen WC, Cheng WC, Lai DM. Loss of Cxcl12/Sdf1 in adult mice decreases the quiescent state of hematopoietic stem/progenitor cells and alters the pattern of hematopoietic regeneration after myelosuppression. Blood (2011) 117:429-39. doi: 10.1182/blood-2010-01266833

25. Ding L, Saunders TL, Enikolopov G, Morrison SJ. Endothelial and perivascular cells maintain haematopoietic stem cells. Nature (2012) 481:457-62. doi: 10.1038/nature 10783

26. Ding L, Morrison SJ. Haematopoietic stem cells and early lymphoid progenitors occupy distinct bone marrow niches. Nature (2013) 495:231-5. doi: 10.1038/nature11885

27. Greenbaum A, Hsu YM, Day RB, Schuettpelz LG, Christopher MJ, Borgerding $\mathrm{JN}$, et al. CXCL12 in early mesenchymal progenitors is required for haematopoietic stem-cell maintenance. Nature (2013) 495:227-30. doi: 10.1038 /nature 11926

28. Nie Y, Waite J, Brewer F, Sunshine MJ, Littman DR, Zou YR. The role of CXCR4 in maintaining peripheral B cell compartments and humoral immunity. J Exp Med (2004) 200:1145-56. doi: 10.1084/jem.20041185

29. Pereira JP, An J, Xu Y, Huang Y, Cyster JG. Cannabinoid receptor 2 mediates the retention of immature B cells in bone marrow sinusoids. Nat Immunol (2009) 10:403-11. doi: 10.1038/ni.1710

30. Beck TC, Gomes AC, Cyster JG, Pereira JP. CXCR4 and a cell-extrinsic mechanism control immature B lymphocyte egress from bone marrow. J Exp Med (2014) 211:2567-81. doi: 10.1084/jem.20140457

31. Springer TA. Traffic signals for lymphocyte recirculation and leukocyte emigration: the multistep paradigm. Cell (1994) 76:301-14. doi: 10.1016/ 0092-8674(94)90337-9

32. Grabovsky V, Feigelson S, Chen C, Bleijs DA, Peled A, Cinamon G, et al. Subsecond induction of alpha4 integrin clustering by immobilized chemokines stimulates leukocyte tethering and rolling on endothelial vascular cell adhesion molecule 1 under flow conditions. J Exp Med (2000) 192:495-506. doi: 10.1084/jem.192.4.495

33. Lim VY, Zehentmeier S, Fistonich C, Pereira JP. A Chemoattractant-Guided Walk Through Lymphopoiesis: From Hematopoietic Stem Cells to Mature B Lymphocytes. Adv Immunol (2017) 134:47-88. doi: 10.1016/bs.ai.2017.02.001

34. Upadhaya S, Krichevsky O, Akhmetzyanova I, Sawai CM, Fooksman DR, Reizis B. Intravital Imaging Reveals Motility of Adult Hematopoietic Stem Cells in the Bone Marrow Niche. Cell Stem Cell (2020) 27:336-45. doi: 10.1016/j.stem.2020.06.003

35. Mandal M, Okoreeh MK, Kennedy DE, Maienschein-Cline M, Ai J, McLean $\mathrm{KC}$, et al. CXCR4 signaling directs Igk recombination and the molecular 
mechanisms of late B lymphopoiesis. Nat Immunol (2019) 20:1393-403. doi: 10.1038/s41590-019-0468-0

36. Baryawno N, Przybylski D, Kowalczyk MS, Kfoury Y, Severe N, Gustafsson $\mathrm{K}$, et al. A Cellular Taxonomy of the Bone Marrow Stroma in Homeostasis and Leukemia. Cell (2019) 177:1915-32.e16. doi: 10.1016/j.cell. 2019.04.040

37. Tikhonova AN, Dolgalev I, Hu H, Sivaraj KK, Hoxha E, Cuesta-Dominguez A, et al. The bone marrow microenvironment at single-cell resolution. Nature (2019) 569:222-8. doi: 10.1038/s41586-019-1104-8

38. Baccin C, Al-Sabah J, Velten L, Helbling PM, Grunschlager F, HernandezMalmierca P, et al. Combined single-cell and spatial transcriptomics reveal the molecular, cellular and spatial bone marrow niche organization. Nat Cell Biol (2020) 22:38-48. doi: 10.1038/s41556-019-0439-6

39. Xavier-Ferrucio J, Krause DS. Concise Review: Bipotent MegakaryocyticErythroid Progenitors: Concepts and Controversies. Stem Cells (2018) 36:1138-45. doi: 10.1002/stem.2834

40. Arinobu Y, Iwasaki H, Gurish MF, Mizuno S, Shigematsu H, Ozawa H, et al. Developmental checkpoints of the basophil/mast cell lineages in adult murine hematopoiesis. Proc Natl Acad Sci USA (2005) 102:18105-10. doi: 10.1073/ pnas. 0509148102

41. Chen CC, Grimbaldeston MA, Tsai M, Weissman IL, Galli SJ. Identification of mast cell progenitors in adult mice. Proc Natl Acad Sci U.S.A. (2005) 102:11408-13. doi: 10.1073/pnas.0504197102

42. Franco CB, Chen CC, Drukker M, Weissman IL, Galli SJ. Distinguishing mast cell and granulocyte differentiation at the single-cell level. Cell Stem Cell (2010) 6:361-8. doi: 10.1016/j.stem.2010.02.013

43. Mukai K, BenBarak MJ, Tachibana M, Nishida K, Karasuyama H, Taniuchi I, et al. Critical role of P1-Runx1 in mouse basophil development. Blood (2012) 120:76-85. doi: 10.1182/blood-2011-12-399113

44. Qi X, Hong J, Chaves L, Zhuang Y, Chen Y, Wang D, et al. Antagonistic regulation by the transcription factors C/EBPalpha and MITF specifies basophil and mast cell fates. Immunity (2013) 39:97-110. doi: 10.1016/ j.immuni.2013.06.012

45. Broudy VC. Stem cell factor and hematopoiesis. Blood (1997) 90:1345-64. doi: 10.1182/blood.V90.4.1345.1345_1345_1364

46. Lin H, Lee E, Hestir K, Leo C, Huang M, Bosch E, et al. Discovery of a cytokine and its receptor by functional screening of the extracellular proteome. Science (2008) 320:807-11. doi: 10.1126/science.1154370

47. Wiktor-Jedrzejczak W, Bartocci A, Ferrante AW Jr., Ahmed-Ansari A, Sell $\mathrm{KW}$, Pollard JW, et al. Total absence of colony-stimulating factor 1 in the macrophage-deficient osteopetrotic (op/op) mouse. Proc Natl Acad Sci USA (1990) 87:4828-32. doi: 10.1073/pnas.87.12.4828

48. Yoshida H, Hayashi S, Kunisada T, Ogawa M, Nishikawa S, Okamura H, et al. The murine mutation osteopetrosis is in the coding region of the macrophage colony stimulating factor gene. Nature (1990) 345:442-4. doi: 10.1038/ 345442a0

49. Geissmann F, Manz MG, Jung S, Sieweke MH, Merad M, Ley K. Development of monocytes, macrophages, and dendritic cells. Science (2010) 327:656-61. doi: 10.1126/science.1178331

50. Stanley ER, Chitu V. CSF-1 receptor signaling in myeloid cells. Cold Spring Harb Perspect Biol (2014) 6:a021857. doi: 10.1101/cshperspect.a021857

51. Yao GQ, Wu JJ, Sun BH, Troiano N, Mitnick MA, Insogna K. The cell surface form of colony-stimulating factor-1 is biologically active in bone in vivo. Endocrinology (2003) 144:3677-82. doi: 10.1210/en.2002-221071

52. Dai XM, Zong XH, Sylvestre V, Stanley ER. Incomplete restoration of colonystimulating factor 1 (CSF-1) function in CSF-1-deficient Csf1op/Csflop mice by transgenic expression of cell surface CSF-1. Blood (2004) 103:1114-23. doi: 10.1182/blood-2003-08-2739

53. Chong SZ, Evrard M, Devi S, Chen J, Lim JY, See P, et al. CXCR4 identifies transitional bone marrow premonocytes that replenish the mature monocyte pool for peripheral responses. J Exp Med (2016) 213:2293-314. doi: 10.1084/ jem.20160800

54. Nakashima T, Hayashi M, Fukunaga T, Kurata K, Oh-Hora M, Feng JQ, et al. Evidence for osteocyte regulation of bone homeostasis through RANKL expression. Nat Med (2011) 17:1231-4. doi: 10.1038/nm.2452

55. Nevius E, Gomes AC, Pereira JP. Inflammatory Cell Migration in Rheumatoid Arthritis: A Comprehensive Review. Clin Rev Allergy Immunol (2015) 51:5978. doi: 10.1007/s12016-015-8520-9
56. Nevius E, Pinho F, Dhodapkar M, Jin H, Nadrah K, Horowitz MC, et al. Oxysterols and EBI2 promote osteoclast precursor migration to bone surfaces and regulate bone mass homeostasis. J Exp Med (2015) 212:1931-46. doi: 10.1084/jem.20150088

57. Anderson D, Murphy KM. Models of dendritic cell development correlate ontogeny with function. Adv Immunol (2019) 143:99-119. doi: 10.1016/ bs.ai.2019.09.001

58. Kohara H, Omatsu Y, Sugiyama T, Noda M, Fujii N, Nagasawa T. Development of plasmacytoid dendritic cells in bone marrow stromal cell niches requires CXCL12-CXCR4 chemokine signaling. Blood (2007) 110:4153-60. doi: 10.1182/blood-2007-04-084210

59. Summers C, Rankin SM, Condliffe AM, Singh N, Peters AM, Chilvers ER. Neutrophil kinetics in health and disease. Trends Immunol (2010) 31:318-24. doi: 10.1016/j.it.2010.05.006

60. Manz MG, Boettcher S. Emergency granulopoiesis. Nat Rev Immunol (2014) 14:302-14. doi: 10.1038/nri3660

61. Herault A, Binnewies M, Leong S, Calero-Nieto FJ, Zhang SY, Kang YA, et al. Myeloid progenitor cluster formation drives emergency and leukaemic myelopoiesis. Nature (2017) 544:53-8. doi: 10.1038/nature21693

62. Ueda Y, Yang K, Foster SJ, Kondo M, Kelsoe G. Inflammation controls B lymphopoiesis by regulating chemokine CXCL12 expression. J Exp Med (2004) 199:47-58. doi: 10.1084/jem.20031104

63. Ueda Y, Kondo M, Kelsoe G. Inflammation and the reciprocal production of granulocytes and lymphocytes in bone marrow. J Exp Med (2005) 201:177180. doi: $10.1084 /$ jem.20041419

64. Kawakami M, Tsutsumi H, Kumakawa T, Abe H, Hirai M, Kurosawa S, et al. Levels of serum granulocyte colony-stimulating factor in patients with infections. Blood (1990) 76:1962-4. doi: 10.1182/blood.V76.10.1962. bloodjournal76101962

65. Cebon J, Layton JE, Maher D, Morstyn G. Endogenous haemopoietic growth factors in neutropenia and infection. Br J Haematol (1994) 86:265-74. doi: 10.1111/j.1365-2141.1994.tb04725.x

66. Chiba Y, Mizoguchi I, Hasegawa H, Ohashi M, Orii N, Nagai T, et al. Regulation of myelopoiesis by proinflammatory cytokines in infectious diseases. Cell Mol Life Sci (2018) 75:1363-76. doi: 10.1007/s00018-0172724-5

67. Calderon L, Boehm T. Synergistic, context-dependent, and hierarchical functions of epithelial components in thymic microenvironments. Cell (2012) 149:159-72. doi: 10.1016/j.cell.2012.01.049

68. Ohnmacht C, Voehringer D. Basophil effector function and homeostasis during helminth infection. Blood (2009) 113:2816-25. doi: 10.1182/blood2008-05-154773

69. Willebrand R, Voehringer D. Regulation of eosinophil development and survival. Curr Opin Hematol (2017) 24:9-15. doi: 10.1097/MOH.0000000000000293

70. Carlens J, Wahl B, Ballmaier M, Bulfone-Paus S, Forster R, Pabst O. Common gamma-chain-dependent signals confer selective survival of eosinophils in the murine small intestine. J Immunol (2009) 183:5600-7. doi: 10.4049/ jimmunol.0801581

71. Moro K, Yamada T, Tanabe M, Takeuchi T, Ikawa T, Kawamoto H, et al. Innate production of $\mathrm{T}(\mathrm{H}) 2$ cytokines by adipose tissue-associated $\mathrm{c}-\mathrm{Kit}(+)$ Sca-1(+) lymphoid cells. Nature (2010) 463:540-4. doi: 10.1038/nature08636

72. Nussbaum JC, Van Dyken SJ, von Moltke J, Cheng LE, Mohapatra A, Molofsky AB, et al. Type 2 innate lymphoid cells control eosinophil homeostasis. Nature (2013) 502:245-8. doi: 10.1038/nature12526

73. de Sauvage FJ, Carver-Moore K, Luoh SM, Ryan A, Dowd M, Eaton DL, et al. Physiological regulation of early and late stages of megakaryocytopoiesis by thrombopoietin. J Exp Med (1996) 183:651-6. doi: 10.1084/jem.183.2.651

74. Decker M, Leslie J, Liu Q, Ding L. Hepatic thrombopoietin is required for bone marrow hematopoietic stem cell maintenance. Sci (New York NY) (2018) 360:106-10. doi: 10.1126/science.aap8861

75. Broudy VC, Lin NL, Kaushansky K. Thrombopoietin (c-mpl ligand) acts synergistically with erythropoietin, stem cell factor, and interleukin-11 to enhance murine megakaryocyte colony growth and increases megakaryocyte ploidy in vitro. Blood (1995) 85:1719-26. doi: 10.1182/blood.V85.7.1719. bloodjournal8571719

76. Muller-Newen G, Stope MB, Kraus T, Ziegler P. Development of platelets during steady state and inflammation. J Leukoc Biol (2017) 101:1109-17. doi: 10.1189/jlb.1RU0916-391RR 
77. Zou YR, Kottmann AH, Kuroda M, Taniuchi I, Littman DR. Function of the chemokine receptor CXCR4 in haematopoiesis and in cerebellar development. Nature (1998) 393:595-9. doi: 10.1038/31269

78. Riviere C, Subra F, Cohen-Solal K, Cordette-Lagarde V, Letestu R, Auclair C, et al. Phenotypic and functional evidence for the expression of CXCR4 receptor during megakaryocytopoiesis. Blood (1999) 93:1511-23. doi: 10.1182/blood.V93.5.1511

79. Bruns I, Lucas D, Pinho S, Ahmed J, Lambert MP, Kunisaki Y, et al. Megakaryocytes regulate hematopoietic stem cell quiescence through CXCL4 secretion. Nat Med (2014) 20:1315-20. doi: 10.1038/nm.3707

80. Zhao M, Perry JM, Marshall H, Venkatraman A, Qian P, He XC, et al. Megakaryocytes maintain homeostatic quiescence and promote post-injury regeneration of hematopoietic stem cells. Nat Med (2014) 20:1321-6. doi: $10.1038 / \mathrm{nm} .3706$

81. Junt T, Schulze H, Chen Z, Massberg S, Goerge T, Krueger A, et al. Dynamic visualization of thrombopoiesis within bone marrow. Science (2007) 317:1767-70. doi: 10.1126/science.1146304

82. Munugalavadla V, Kapur R. Role of c-Kit and erythropoietin receptor in erythropoiesis. Crit Rev Oncol Hematol (2005) 54:63-75. doi: 10.1016/ j.critrevonc.2004.11.005

83. Ma Q, Jones D, Borghesani PR, Segal RA, Nagasawa T, Kishimoto T, et al. Impaired B-lymphopoiesis, myelopoiesis, and derailed cerebellar neuron migration in CXCR4- and SDF-1-deficient mice. Proc Natl Acad Sci USA (1998) 95:9448-53. doi: 10.1073/pnas.95.16.9448

84. Tachibana K, Hirota S, Iizasa H, Yoshida H, Kawabata K, Kataoka Y, et al. The chemokine receptor CXCR4 is essential for vascularization of the gastrointestinal tract. Nature (1998) 393:591-4. doi: 10.1038/31261

85. Slifka MK, Antia R, Whitmire JK, Ahmed R. Humoral immunity due to longlived plasma cells. Immunity (1998) 8:363-72. doi: 10.1016/S1074-7613(00) 80541-5

86. Slifka MK, Matloubian M, Ahmed R. Bone marrow is a major site of longterm antibody production after acute viral infection. J Virol (1995) 69:1895902. doi: 10.1128/JVI.69.3.1895-1902.1995

87. Höfer T, Muehlinghaus G, Moser K, Yoshida T, H EM, Hebel K, et al. Adaptation of humoral memory. Immunol Rev (2006) 211:295-302. doi: 10.1111/j.0105-2896.2006.00380.x

88. Lightman SM, Utley A, Lee KP. Survival of Long-Lived Plasma Cells (LLPC): Piecing Together the Puzzle. Front Immunol (2019) 10:965. doi: 10.3389/ fimmu.2019.00965

89. Minges Wols HA, Underhill GH, Kansas GS, Witte PL. The role of bone marrow-derived stromal cells in the maintenance of plasma cell longevity. J Immunol (2002) 169:4213-21. doi: 10.4049/jimmunol.169.8.4213

90. Cassese G, Arce S, Hauser AE, Lehnert K, Moewes B, Mostarac M, et al. Plasma cell survival is mediated by synergistic effects of cytokines and adhesion-dependent signals. J Immunol (2003) 171:1684-90. doi: 10.4049/ jimmunol.171.4.1684

91. Schuh W, Mielenz D, Jack HM. Unraveling the mysteries of plasma cells. $A d v$ Immunol (2020) 146:57-107. doi: 10.1016/bs.ai.2020.01.002

92. O'Connor BP, Raman VS, Erickson LD, Cook WJ, Weaver LK, Ahonen C, et al. BCMA is essential for the survival of long-lived bone marrow plasma cells. J Exp Med (2004) 199:91-8. doi: 10.1084/jem.20031330

93. Peperzak V, Vikström I, Walker J, Glaser SP, LePage M, Coquery CM, et al. Mcl-1 is essential for the survival of plasma cells. Nat Immunol (2013) 14:2907. doi: 10.1038/ni.2527

94. Benson MJ, Dillon SR, Castigli E, Geha RS, Xu S, Lam KP, et al. Cutting edge: the dependence of plasma cells and independence of memory B cells on BAFF and APRIL. J Immunol (2008) 180:3655-9. doi: 10.4049/jimmunol. 180.6.3655

95. Mackay F, Schneider P, Rennert P, Browning J. BAFF AND APRIL: a tutorial on B cell survival. Annu Rev Immunol (2003) 21:231-64. doi: 10.1146/ annurev.immunol.21.120601.141152

96. Ingold K, Zumsteg A, Tardivel A, Huard B, Steiner QG, Cachero TG, et al. Identification of proteoglycans as the APRIL-specific binding partners. J Exp Med (2005) 201:1375-83. doi: 10.1084/jem.20042309

97. Day ES, Cachero TG, Qian F, Sun Y, Wen D, Pelletier M, et al. Selectivity of BAFF/BLyS and APRIL for binding to the TNF family receptors BAFFR/BR3 and BCMA. Biochemistry (2005) 44:1919-31. doi: 10.1021/ bi048227k
98. Schneider P, Takatsuka H, Wilson A, Mackay F, Tardivel A, Lens S, et al. Maturation of marginal zone and follicular B cells requires B cell activating factor of the tumor necrosis factor family and is independent of B cell maturation antigen. J Exp Med (2001) 194:1691-7. doi: 10.1084/ jem.194.11.1691

99. Matthes T, Dunand-Sauthier I, Santiago-Raber ML, Krause KH, Donze O, Passweg J, et al. Production of the plasma-cell survival factor a proliferation-inducing ligand (APRIL) peaks in myeloid precursor cells from human bone marrow. Blood (2011) 118:1838-44. doi: 10.1182/ blood-2011-01-332940

100. Belnoue E, Tougne C, Rochat AF, Lambert PH, Pinschewer DD, Siegrist CA. Homing and adhesion patterns determine the cellular composition of the bone marrow plasma cell niche. J Immunol (2012) 188:1283-91. doi: 10.4049/jimmunol.1103169

101. Chu VT, Fröhlich A, Steinhauser G, Scheel T, Roch T, Fillatreau S, et al. Eosinophils are required for the maintenance of plasma cells in the bone marrow. Nat Immunol (2011) 12:151-9. doi: 10.1038/ni.1981

102. Winter O, Moser K, Mohr E, Zotos D, Kaminski H, Szyska M, et al. Megakaryocytes constitute a functional component of a plasma cell niche in the bone marrow. Blood (2010) 116:1867-75. doi: 10.1182/blood-2009-12259457

103. Belnoue E, Pihlgren M, McGaha TL, Tougne C, Rochat AF, Bossen C, et al. APRIL is critical for plasmablast survival in the bone marrow and poorly expressed by early-life bone marrow stromal cells. Blood (2008) 111:2755-64. doi: 10.1182/blood-2007-09-110858

104. Jourdan M, Cren M, Robert N, Bolloré K, Fest T, Duperray C, et al. IL-6 supports the generation of human long-lived plasma cells in combination with either APRIL or stromal cell-soluble factors. Leukemia (2014) 28:164756. doi: 10.1038/leu.2014.61

105. Rozanski CH, Arens R, Carlson LM, Nair J, Boise LH, Chanan-Khan AA, et al. Sustained antibody responses depend on $\mathrm{CD} 28$ function in bone marrow-resident plasma cells. J Exp Med (2011) 208:1435-46. doi: 10.1084/jem.20110040

106. Cariappa A, Mazo IB, Chase C, Shi HN, Liu H, Li Q, et al. Perisinusoidal B cells in the bone marrow participate in T-independent responses to bloodborne microbes. Immunity (2005) 23:397-407. doi: 10.1016/ j.immuni.2005.09.004

107. Moreau JM, Berger A, Nelles ME, Mielnik M, Furlonger C, Cen SY, et al. Inflammation rapidly reorganizes mouse bone marrow $\mathrm{B}$ cells and their environment in conjunction with early IgM responses. Blood (2015) 126:1184-92. doi: 10.1182/blood-2015-03-635805

108. Hargreaves DC, Hyman PL, Lu TT, Ngo VN, Bidgol A, Suzuki G, et al. A coordinated change in chemokine responsiveness guides plasma cell movements. J Exp Med (2001) 194:45-56. doi: 10.1084/jem.194.1.45

109. Kabashima K, Haynes NM, Xu Y, Nutt SL, Allende ML, Proia RL, et al. Plasma cell S1P1 expression determines secondary lymphoid organ retention versus bone marrow tropism. J Exp Med (2006) 203:2683-90. doi: 10.1084/ jem.20061289

110. Cyster JG. Homing of antibody secreting cells. Immunol Rev (2003) 194:4860. doi: 10.1034/j.1600-065X.2003.00041.x

111. Tokoyoda K, Egawa T, Sugiyama T, Choi BI, Nagasawa T. Cellular niches controlling B lymphocyte behavior within bone marrow during development. Immunity (2004) 20:707-18. doi: 10.1016/j.immuni. 2004.05.001

112. Zehentmeier S, Roth K, Cseresnyes Z, Sercan O, Horn K, Niesner RA, et al. Static and dynamic components synergize to form a stable survival niche for bone marrow plasma cells. Eur J Immunol (2014) 44:2306-17. doi: 10.1002/ eji.201344313

113. Nguyen DC, Garimalla S, Xiao H, Kyu S, Albizua I, Galipeau J, et al. Factors of the bone marrow microniche that support human plasma cell survival and immunoglobulin secretion. Nat Commun (2018) 9:3698. doi: 10.1038/ s41467-018-05853-7

114. van Spriel AB, de Keijzer S, van der Schaaf A, Gartlan KH, Sofi M, Light A, et al. The tetraspanin CD37 orchestrates the alpha(4)beta(1) integrin-Akt signaling axis and supports long-lived plasma cell survival. Sci Signal (2012) 5:ra82. doi: 10.1126/scisignal.2003113

115. Chang HD, Tokoyoda K, Radbruch A. Immunological memories of the bone marrow. Immunol Rev (2018) 283:86-98. doi: 10.1111/imr.12656 
116. Sapoznikov A, Pewzner-Jung Y, Kalchenko V, Krauthgamer R, Shachar I, Jung S. Perivascular clusters of dendritic cells provide critical survival signals to B cells in bone marrow niches. Nat Immunol (2008) 9:388-95. doi: $10.1038 /$ ni1571

117. Wilmore JR, Allman D. Here, There, and Anywhere? Arguments for and against the Physical Plasma Cell Survival Niche. J Immunol (2017) 199:83945. doi: 10.4049/jimmunol.1700461

118. Meng L, Almeida LN, Clauder AK, Lindemann T, Luther J, Link C, et al. Bone Marrow Plasma Cells Modulate Local Myeloid-Lineage Differentiation via IL-10. Front Immunol (2019) 10:1183. doi: 10.3389/fimmu.2019.01183

119. Pioli PD, Casero D, Montecino-Rodriguez E, Morrison SL, Dorshkind K. Plasma Cells Are Obligate Effectors of Enhanced Myelopoiesis in Aging Bone Marrow. Immunity (2019) 51:351-66.e6. doi: 10.1016/j.immuni.2019.06.006

120. Carlson CM, Endrizzi BT, Wu J, Ding X, Weinreich MA, Walsh ER, et al. Kruppel-like factor 2 regulates thymocyte and T-cell migration. Nature (2006) 442:299-302. doi: 10.1038/nature04882

121. Bai A, Hu H, Yeung M, Chen J. Kruppel-like factor 2 controls T cell trafficking by activating L-selectin (CD62L) and sphingosine-1-phosphate receptor 1 transcription. JImmunol (2007) 178:7632-9. doi: 10.4049/jimmunol.178.12.7632

122. Mueller SN, Germain RN. Stromal cell contributions to the homeostasis and functionality of the immune system. Nat Rev Immunol (2009) 9:618-29. doi: $10.1038 /$ nri2588

123. Mendoza A, Fang V, Chen C, Serasinghe M, Verma A, Muller J, et al. Lymphatic endothelial S1P promotes mitochondrial function and survival in naive T cells. Nature (2017) 546:158-61. doi: 10.1038/nature22352

124. Arojo OA, Ouyang X, Liu D, Meng T, Kaech SM, Pereira JP, et al. Active mTORC2 Signaling in Naive T Cells Suppresses Bone Marrow Homing by Inhibiting CXCR4 Expression. J Immunol (2018) 201:908-15. doi: 10.4049/ jimmunol.1800529

125. Becker TC, Wherry EJ, Boone D, Murali-Krishna K, Antia R, Ma A, et al. Interleukin 15 is required for proliferative renewal of virus-specific memory CD8 T cells. J Exp Med (2002) 195:1541-8. doi: 10.1084/jem.20020369

126. Seddon B, Tomlinson P, Zamoyska R. Interleukin 7 and T cell receptor signals regulate homeostasis of CD4 memory cells. Nat Immunol (2003) 4:680-6. doi: 10.1038/ni946

127. Alves NL, Richard-Le Goff O, Huntington ND, Sousa AP, Ribeiro VS, Bordack A, et al. Characterization of the thymic IL-7 niche in vivo. Proc Natl Acad Sci USA (2009) 106:1512-7. doi: 10.1073/pnas.0809559106

128. Mazzucchelli RI, Warming S, Lawrence SM, Ishii M, Abshari M, Washington $\mathrm{AV}$, et al. Visualization and identification of IL-7 producing cells in reporter mice. PloS One (2009) 4:e7637. doi: 10.1371/journal.pone.0007637

129. Repass JF, Laurent MN, Carter C, Reizis B, Bedford MT, Cardenas K, et al. IL7-hCD25 and IL7-Cre BAC transgenic mouse lines: new tools for analysis of IL-7 expressing cells. Genesis (2009) 47:281-7. doi: 10.1002/dvg.20497

130. Becker TC, Coley SM, Wherry EJ, Ahmed R. Bone marrow is a preferred site for homeostatic proliferation of memory CD8 T cells. J Immunol (2005) 174:1269-73. doi: 10.4049/jimmunol.174.3.1269

131. Mazo IB, Honczarenko M, Leung H, Cavanagh LL, Bonasio R, Weninger W, et al. Bone marrow is a major reservoir and site of recruitment for central memory CD8+ T cells. Immunity (2005) 22:259-70. doi: 10.1016/ j.immuni.2005.01.008

132. Tokoyoda K, Zehentmeier S, Hegazy AN, Albrecht I, Grun JR, Lohning M, et al. Professional memory CD4+ T lymphocytes preferentially reside and rest in the bone marrow. Immunity (2009) 30:721-30. doi: 10.1016/ j.immuni.2009.03.015

133. Chaix J, Nish SA, Lin WH, Rothman NJ, Ding L, Wherry EJ, et al. Cutting edge: CXCR4 is critical for CD8+ memory T cell homeostatic self-renewal but not rechallenge self-renewal. J Immunol (2014) 193:1013-6. doi: 10.4049/ jimmunol.1400488

134. Glatman Zaretsky A, Konradt C, Depis F, Wing JB, Goenka R, Atria DG, et al. T Regulatory Cells Support Plasma Cell Populations in the Bone Marrow. Cell Rep (2017) 18:1906-16. doi: 10.1016/j.celrep.2017.01.067

135. Fujisaki J, Wu J, Carlson AL, Silberstein L, Putheti P, Larocca R, et al. In vivo imaging of Treg cells providing immune privilege to the haematopoietic stem-cell niche. Nature (2011) 474:216-9. doi: 10.1038/nature10160

136. Fischer L, Herkner C, Kitte R, Dohnke S, Riewaldt J, Kretschmer K, et al. Foxp3(+) Regulatory T Cells in Bone and Hematopoietic Homeostasis. Front Endocrinol (Lausanne) (2019) 10:578. doi: 10.3389/fendo.2019.00578
137. Hirata Y, Furuhashi K, Ishii H, Li HW, Pinho S, Ding L, et al. CD150(high) Bone Marrow Tregs Maintain Hematopoietic Stem Cell Quiescence and Immune Privilege via Adenosine. Cell Stem Cell (2018) 22:445-53.e5. doi: 10.1016/j.stem.2018.01.017

138. Reif K, Ekland EH, Ohl L, Nakano H, Lipp M, Forster R, et al. Balanced responsiveness to chemoattractants from adjacent zones determines B-cell position. Nature (2002) 416:94-9. doi: 10.1038/416094a

139. Cyster JG. Chemokines, sphingosine-1-phosphate, and cell migration in secondary lymphoid organs. Annu Rev Immunol (2005) 23:127-59. doi: 10.1146/annurev.immunol.23.021704.115628

140. Hernandez PA, Gorlin RJ, Lukens JN, Taniuchi S, Bohinjec J, Francois F, et al. Mutations in the chemokine receptor gene CXCR4 are associated with WHIM syndrome, a combined immunodeficiency disease. Nat Genet (2003) 34:70-4. doi: 10.1038/ng1149

141. Balabanian K, Lagane B, Pablos JL, Laurent L, Planchenault T, Verola O, et al. WHIM syndromes with different genetic anomalies are accounted for by impaired CXCR4 desensitization to CXCL12. Blood (2005) 105:2449-57. doi: 10.1182/blood-2004-06-2289

142. Haribabu B, Richardson RM, Fisher I, Sozzani S, Peiper SC, Horuk R, et al. Regulation of human chemokine receptors CXCR4. Role of phosphorylation in desensitization and internalization. J Biol Chem (1997) 272:28726-31. doi: $10.1074 /$ jbc.272.45.28726

143. Signoret N, Rosenkilde MM, Klasse PJ, Schwartz TW, Malim MH, Hoxie JA, et al. Differential regulation of CXCR4 and CCR5 endocytosis. J Cell Sci (1998) 111(Pt 18):2819-30. doi: 10.1083/jcb.151.6.1281

144. Lagane B, Chow KY, Balabanian K, Levoye A, Harriague J, Planchenault T, et al. CXCR4 dimerization and beta-arrestin-mediated signaling account for the enhanced chemotaxis to CXCL12 in WHIM syndrome. Blood (2008) 112:34-44. doi: 10.1182/blood-2007-07-102103

145. Beaussant Cohen S, Fenneteau O, Plouvier E, Rohrlich PS, Daltroff G, Plantier I, et al. Description and outcome of a cohort of 8 patients with WHIM syndrome from the French Severe Chronic Neutropenia Registry. Orphanet J Rare Dis (2012) 7:71. doi: 10.1186/1750-1172-7-71

146. Balabanian K, Brotin E, Biajoux V, Bouchet-Delbos L, Lainey E, Fenneteau $\mathrm{O}$, et al. Proper desensitization of CXCR4 is required for lymphocyte development and peripheral compartmentalization in mice. Blood (2012) 119:5722-30. doi: 10.1182/blood-2012-01-403378

147. McDermott DH, Pastrana DV, Calvo KR, Pittaluga S, Velez D, Cho E, et al. Plerixafor for the Treatment of WHIM Syndrome. N Engl J Med (2019) 380:163-70. doi: 10.1056/NEJMoa1808575

148. McDermott DH, Gao JL, Liu Q, Siwicki M, Martens C, Jacobs P, et al. Chromothriptic cure of WHIM syndrome. Cell (2015) 160:686-99. doi: 10.1016/j.cell.2015.01.014

149. Freitas C, Wittner M, Nguyen J, Rondeau V, Biajoux V, Aknin ML, et al. Lymphoid differentiation of hematopoietic stem cells requires efficient Cxcr4 desensitization. J Exp Med (2017) 214:2023-40. doi: 10.1084/ jem.20160806

150. Mendez-Ferrer S, Bonnet D, Steensma DP, Hasserjian RP, Ghobrial IM, Gribben JG, et al. Bone marrow niches in haematological malignancies. Nat Rev Cancer (2020) 20:285-98. doi: 10.1038/s41568-020-0245-2

151. Zhang B, Ho YW, Huang Q, Maeda T, Lin A, Lee SU, et al. Altered microenvironmental regulation of leukemic and normal stem cells in chronic myelogenous leukemia. Cancer Cell (2012) 21:577-92. doi: 10.1016/j.ccr.2012.02.018

152. Schepers K, Pietras EM, Reynaud D, Flach J, Binnewies M, Garg T, et al. Myeloproliferative neoplasia remodels the endosteal bone marrow niche into a self-reinforcing leukemic niche. Cell Stem Cell (2013) 13:285-99. doi: 10.1016/j.stem.2013.06.009

153. Thiele J, Kvasnicka HM. Myelofibrosis in chronic myeloproliferative disorders-dynamics and clinical impact. Histol histopathol (2006) 21:1367-78. doi: 10.14670/HH-21.1367

154. Klein C, Zwick A, Kissel S, Forster CU, Pfeifer D, Follo M, et al. Ptch2 loss drives myeloproliferation and myeloproliferative neoplasm progression. J Exp Med (2016) 213:273-90. doi: 10.1084/jem.20150556

155. Colmone A, Amorim M, Pontier AL, Wang S, Jablonski E, Sipkins DA. Leukemic cells create bone marrow niches that disrupt the behavior of normal hematopoietic progenitor cells. Sci (New York NY) (2008) 322:1861-5. doi: 10.1126/science. 1164390 
156. Arranz L, Sanchez-Aguilera A, Martin-Perez D, Isern J, Langa X, Tzankov A, et al. Neuropathy of haematopoietic stem cell niche is essential for myeloproliferative neoplasms. Nature (2014) 512:78-81. doi: 10.1038/ nature 13383

157. Wetzler M, Kurzrock R Fau - Estrov Z, Estrov Z Fau - Kantarjian H, Kantarjian H Fau - Gisslinger H, Gisslinger H Fau - Underbrink MP, Underbrink Mp Fau - Talpaz M, et al. Altered levels of interleukin-1 beta and interleukin-1 receptor antagonist in chronic myelogenous leukemia: clinical and prognostic correlates. Blood (1994) 84:3142-7. doi: 10.1182/ blood.V84.9.3142.bloodjournal8493142

158. Espinoza-Hernandez L, Cruz-Rico J, Benitez-Aranda H, Martinez-Jaramillo G, Rodriguez-Zepeda MC, Velez-Ruelas MA, et al. In vitro characterization of the hematopoietic system in pediatric patients with acute lymphoblastic leukemia. Leuk Res (2001) 25:295-303. doi: 10.1016/S0145-2126(00)00141-7

159. Laperrousaz B, Jeanpierre S, Sagorny K, Voeltzel T, Ramas S, Kaniewski B, et al. Primitive CML cell expansion relies on abnormal levels of BMPs provided by the niche and on BMPRIb overexpression. Blood (2013) 122:3767-77. doi: 10.1182/blood-2013-05-501460

160. Katayama Y, Battista M, Kao WM, Hidalgo A, Peired AJ, Thomas SA, et al. Signals from the sympathetic nervous system regulate hematopoietic stem cell egress from bone marrow. Cell (2006) 124:407-21. doi: 10.1016/ j.cell.2005.10.041

161. Hanoun M, Zhang D, Mizoguchi T, Pinho S, Pierce H, Kunisaki Y, et al. Acute myelogenous leukemia-induced sympathetic neuropathy promotes malignancy in an altered hematopoietic stem cell niche. Cell Stem Cell (2014) 15:365-75. doi: 10.1016/j.stem.2014.06.020

162. Chandran P, Le Y, Li Y, Sabloff M, Mehic J, Rosu-Myles M, et al. Mesenchymal stromal cells from patients with acute myeloid leukemia have altered capacity to expand differentiated hematopoietic progenitors. Leuk Res (2015) 39:486-93. doi: 10.1016/j.leukres.2015.01.013

163. Geyh S, Rodriguez-Paredes M, Jager P, Khandanpour C, Cadeddu RP, Gutekunst J, et al. Functional inhibition of mesenchymal stromal cells in acute myeloid leukemia. Leukemia (2016) 30:683-91. doi: 10.1038/leu.2015.325

164. Miraki-Moud F, Anjos-Afonso F Fau - Hodby KA, Hodby Ka Fau Griessinger E, Griessinger E Fau - Rosignoli G, Rosignoli G Fau Lillington D, Lillington D Fau - Jia L, et al. Acute myeloid leukemia does not deplete normal hematopoietic stem cells but induces cytopenias by impeding their differentiation. Proc Natl Acad Sci USA (2013) 110:13576-81. doi: 10.1073/pnas.1301891110

165. Bam R, Ling W, Khan S, Pennisi A, Venkateshaiah SU, Li X, et al. Role of Bruton's tyrosine kinase in myeloma cell migration and induction of bone disease. Am J Hematol (2013) 88:463-71. doi: 10.1002/ajh.23433

166. Ponader S, Chen SS, Buggy JJ, Balakrishnan K, Gandhi V, Wierda WG, et al. The Bruton tyrosine kinase inhibitor PCI-32765 thwarts chronic lymphocytic leukemia cell survival and tissue homing in vitro and in vivo. Blood (2012) 119:1182-9. doi: 10.1182/blood-2011-10-386417
167. Lane SW, Wang YJ, Lo Celso C, Ragu C, Bullinger L, Sykes SM, et al. Differential niche and Wnt requirements during acute myeloid leukemia progression. Blood (2011) 118:2849-56. doi: 10.1182/blood-2011-03-345165

168. Dong L, Yu WM, Zheng H, Loh ML, Bunting ST, Pauly M, et al. Leukaemogenic effects of Ptpn11 activating mutations in the stem cell microenvironment. Nature (2016) 539:304-8. doi: 10.1038/nature20131

169. Raaijmakers MH, Mukherjee S, Guo S, Zhang S, Kobayashi T, Schoonmaker JA, et al. Bone progenitor dysfunction induces myelodysplasia and secondary leukaemia. Nature (2010) 464:852-7. doi: 10.1038/nature08851

170. Xiao P, Dolinska M, Sandhow L, Kondo M, Johansson AS, Bouderlique T, et al. Sipal deficiency-induced bone marrow niche alterations lead to the initiation of myeloproliferative neoplasm. Blood Adv (2018) 2:534-48. doi: 10.1182/bloodadvances.2017013599

171. Walkley CR, Olsen GH, Dworkin S, Fabb SA, Swann J, McArthur GA, et al. A microenvironment-induced myeloproliferative syndrome caused by retinoic acid receptor gamma deficiency. Cell (2007) 129:1097-110. doi: 10.1016/j.cell.2007.05.014

172. Kode A, Manavalan JS, Mosialou I, Bhagat G, Rathinam CV, Luo N, et al. Leukaemogenesis induced by an activating beta-catenin mutation in osteoblasts. Nature (2014) 506:240-4. doi: 10.1038/nature12883

173. Xu L, Yao D, Tan J, He Z, Yu Z, Chen J, et al. Memory T cells skew toward terminal differentiation in the CD8+ $\mathrm{T}$ cell population in patients with acute myeloid leukemia. J Hematol Oncol (2018) 11:93. doi: 10.1186/s13045-0180636-y

174. Lamble AJ, Kosaka Y, Laderas T, Maffit A, Kaempf A, Brady LK, et al. Reversible suppression of $\mathrm{T}$ cell function in the bone marrow microenvironment of acute myeloid leukemia. Proc Natl Acad Sci USA (2020) 117:14331-41. doi: 10.1073/pnas.1916206117

175. Shimoto M, Sugiyama T, Nagasawa T. Numerous niches for hematopoietic stem cells remain empty during homeostasis. Blood (2017) 129:2124-31. doi: 10.1182/blood-2016-09-740563

176. Christodoulou C, Spencer JA, Yeh SA, Turcotte R, Kokkaliaris KD, Panero R, et al. Live-animal imaging of native haematopoietic stem and progenitor cells. Nature (2020) 578:278-83. doi: 10.1038/s41586-020-1971-z

Conflict of Interest: The authors declare that the research was conducted in the absence of any commercial or financial relationships that could be construed as a potential conflict of interest.

Copyright (c) 2020 Miao, Lim, Kothapalli, Ma, Fossati, Zehentmeier, Sun and Pereira. This is an open-access article distributed under the terms of the Creative Commons Attribution License (CC BY). The use, distribution or reproduction in other forums is permitted, provided the original author(s) and the copyright owner(s) are credited and that the original publication in this journal is cited, in accordance with accepted academic practice. No use, distribution or reproduction is permitted which does not comply with these terms. 